\title{
URBAN RENAISSANCE : THE ROLE OF URBAN REGENERATION IN EUROPE'S URBAN DEVELOPMENT FUTURE
}

\author{
A B S T R A C T
}

Integrated Urban Regeneration can make an enormous contribution to the resolution of main problems such as the current economic situation, global warming, energy consumption, social exclusion and urban decline. The principles of urban regeneration are well established. The experience of urban regeneration in European Cities and Towns is well proven. This will only be achieved if concerted action is taken across all European countries. Experience has shown the benefit of European programs applied to Cities and Towns. There is therefore an opportunity for the creation of a European program to provide dynamics Urban Regeneration all over Europe to deliver the required Urban Renaissance. 


\section{INTRODUCTION}

After the reconstruction following the World War Two, western European countries exhibited a great economic growth and the welfare state. The families could live better and consume much more. Housing conditions have much improved in several countries in Europe.

The families could afford better and bigger houses. At the same time agriculture was more mechanized and the workers looked for jobs in the manufacturing industry and in the services. They looked for jobs in the cities. The cities developed new industrial, services, shopping and housing areas.

After the 1973 and the 1979 oil prices crises, these trends changed. The increase of energy costs, the decline of consumption, the international recession and the intense competition gave rise to unemployment and social crises. Many traditional industries declined or became bankrupt. Some looked for better locations, less expensive rents and lower salaries, or in some industries for more specialized workers. Harbors started using new technologies such as containers and ships became larger and larger. Railway transport lost business to road transport. Governments did not invest in these areas. Consequently physical and social infrastructure became obsolete. Obsolescent urban areas emerged in the inner cities, along waterfronts and spread more widely. Local tax bases declined and were not sufficient to upgrade these areas. Private investors no longer invested in these areas. These physical problems were exacerbated by social ones, such as, crime, poverty, social exclusion and racism. These problems affected cities and regions. In recent years the globalization of production and investment accelerated these trends.

In Europe, most cities therefore changed rapidly, in the last 30 years. The economic bases of cities are being restructured. City economies are no longer primarily based on manufacturing industry. The process of suburbanization attracted many functions from central parts towards the periphery. These two trends gave rise to abandoned buildings, factories and harbors, to unemployment and social problems and to urban and environmental degradation.

Peripheral housing estates exhibited more attractive houses, less expensive and new, with better social facilities, infrastructure and services. Thus many households moved away from inner cities. These changes were also related to changes in the nature and structure of families:

- people living longer;

- the number of children decreasing; 
- an increasing number of one person families.

And so the number of households has been increasing rapidly, even where there was a declining population.

The Urban Regeneration has been a key policy response to these problems. Its general objective is to break the cycle of urban decline, by promoting the growth of new economic activities, creation of new activities and jobs, reduction of social problems, promotion of social inclusion, improvement of urban quality and upgrade of the urban environment. In order to address these objectives it has been necessary to support urban regeneration through stable institutional, economical, financial and technical enterprises and/or corporations. The European city is no longer a place of traditional industry but a place of consumption, scientific development, innovation, culture and recreation.

The scientific development is based:

- on the expansion of Institutes and Universities;

- on clusters of knowledge, like: biomedical, space, ICT and material sciences;

- networking between new industries, the private sector, universities and local, regional and national authorities;

- on the dissemination of knowledge;

- on technology transfer; and

- on the new industries like: life sciences as biotechnology, neurosciences, vascular medicine, bio banks, experts centers of imaging; communications; new media; creative industries like: fashion, design, photography, and performing arts.

In some European cities industry has been substituted by tertiary and quaternary sectors of economy. Cultural heritage has also been the bases of the growth of tourism and leisure industries.

\section{URBAN REGENERATION ACROSS HISTORY}

In the last 150 years urban regeneration was related to:

- the improvement of public health, mainly by water treatment and supply, sewerage, waste collection and paved and clean streets;

- the construction of new urban infrastructure and facilities such as rail stations, schools, university faculties, hospitals, etc;

- the provision of housing establishment of minimum standards; 
Figure 1

KNSM Island, Eastern Harbor District Amsterdam - after

Figure 2

Salford Bridge, Manchester - after

Figure 3

Chester Road, Manchester - Strategic Development Initiative

Figure 4

Chester Road, Manchester - after

Figure 5 Borneo \& Sporenburg Eastern Harbor District Amsterdam - after
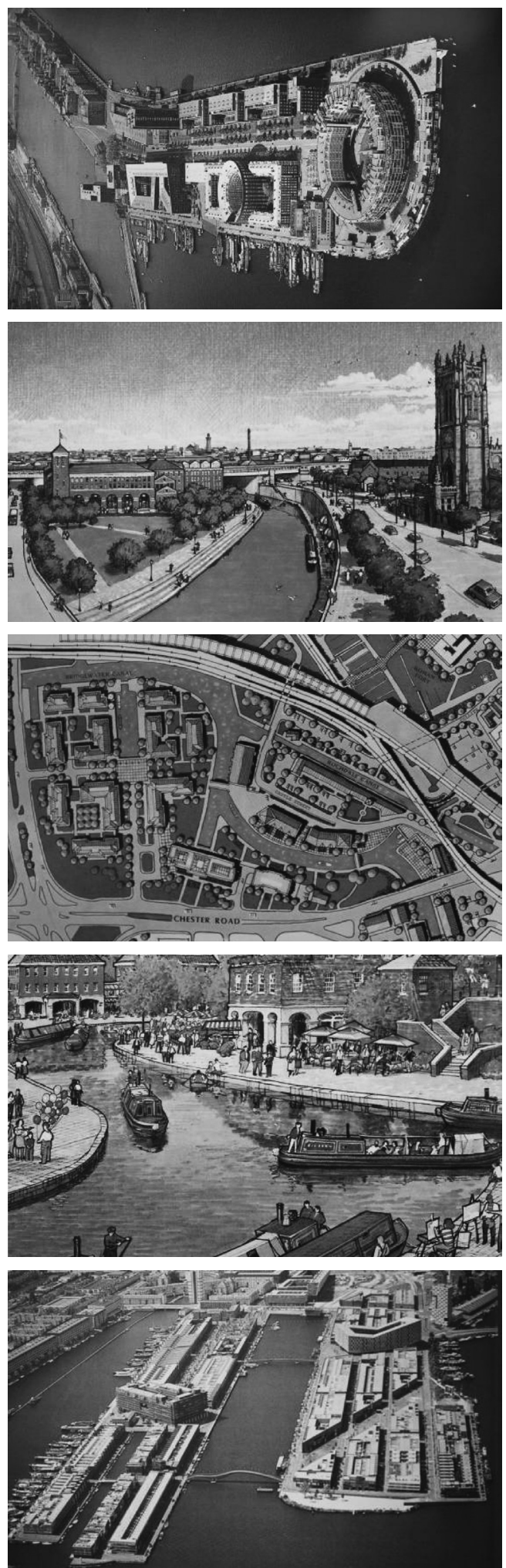
- the control of urban growth and expansion, as a consequence of the development of urban transport systems;

- the modern urban design, reconstruction of war time damage, especially after the World War Two;

- the construction of new road traffic infrastructures;

- the regeneration of obsolete industrial and waterfront areas;

- the social inclusion;

- the objectives, principles and technologies of urban sustainable development.

Some of these are characteristic of an epoch, others are present in more than one epoch and others are always present.

These themes dominated previous eras of urban change and policy (Roberts, P., 2006, p.10):

- relationship between physical conditions and social and political response;

- housing and health;

- linking social improvements and economic progress;

- optimum land use and control of urban expansion;

- changing the role of urban policy.

All over Europe, in the last decades, new laws were enacted, new programs were created and new interventions were in the field.

The relation between urban regeneration and the planning system differs from country to country. In some countries like Belgium and the Netherlands urban regeneration is an extension of urban planning system. In UK it appears to be a virtually separated arm of public policy. (Couch, C., 2003, p. 6).

\section{EU AND URBAN REGENERATION}

The EU does not have a mandate in urban policy, but is engaged in some urban matters. In 1990 the Green Paper on the Urban Environment was published. It served as an orientation for several directives and political actions. The Community Initiative Program Interreg and the Urban Pilot Projects were initiated. Urban regeneration was focused on urban pilot projects and URBAN I and URBAN II. It was also included in several projects funded by the European Regional Development Fund, ERDF. The Trans-European Networks, TEN, was important for economic growth and employment in transport, telecommunications and energy fields, in regions covered by objective 1 . 
The urban pilot projects funded from 1990 to 199633 projects in the first phase and 26 projects in the second phase, in total investment of 202 million Euros. The projects had to be innovative, contribute to regional development, be on urban planning or regeneration with European interest and contain a demonstrated potential of a proposal.

URBAN I, 1994-1999, funded 900 million Euros, in 118 programs, with a total investment of 1,800 million Euros, covering 3 million inhabitants, 52\% in the cities of more than 250000 inhabitants (large cities); 51\% in the cities between 100000 and 250000 inhabitants (medium size cities), and 17\% in the cities with less than 100000 inhabitants (small size cities).

URBAN I funded different strategies (Drewe, P., 2008, p.186):

- integrated physical infrastructures, social inclusion, and environmental improvements - 44,8\%;

- integrated approaches with a focus on social or economic or physical or environmental;

- flagship approach - 10,4\%;

- integrated community group approach - $18,4 \%$.

URBAN II, 2000-2006, funded 700 million Euros, in 70 programs with a total investment of 1,580 million Euros, covering 2,2 million inhabitants, 39\% of large cities; $44 \%$ of medium size cities; and $17 \%$ of small size cities.

The objectives of URBAN II were:

- "to formulate and implement innovative strategies for sustainable economic and social regeneration of small and medium-sized towns and cites or of distressed urban neighborhoods in larger cities;

- to enhance and exchange knowledge and experience in relation to sustainable urban regeneration and development in the areas concerned".

The urban regeneration strategies of URBAN II projects should follow the following principles:

- "sufficient critical mass of population and associated support structures to facilitate the formulation and implementation of innovative urban development programs;

- strong local partnership to define challenges, strategy and priorities, allocate resources and monitor and evaluate the strategy. Partnerships are wide and include economic and social partners, non-governmental organizations and residents' groupings; 
- an integrated territorial approach linked to development strategies for the wider urban area or region;

- integration of the economic, social and environmental, security and transport aspects, including equality of access to education and training opportunities;

- promotion of equal opportunities between men and women;

- complementarities with the main forms of assistance under the Structural Funds and other Community initiatives" (Interreg III, Leader+, Equal).

URBAN II considered that at least three of these criteria should be fulfilled for an area to be eligible:

- "a low level of economic activity and a specific need for conversion due to local economic and social difficulties;

- a high level of long-term unemployment, poverty and exclusion;

- a low level of education, significant skills deficiencies and high dropout-rates from school;

- a high number of immigrants, ethnic and minority groups, or refugees;

- a high level of criminality and delinquency;

- precarious demographic trends;

- a particularly degraded environment".

Urban regeneration could benefit from programs for industry like Rechal, for coal, Retex for textiles and Konver, for defense. Social problems could be included in programs from DGV and environmental ones from DG XI and Discus and Lasala.

The INTERREG program also included urban regeneration programs like: the Urban regeneration Network and the Living in Towns. AS reagrds the Urban Environment it called for several sustainable tools, like compact cities, the control of urban expansion, the reuse of land and urban environments. DG 11, Environment, DG 16, Regional Affairs and DG 5.

The European Spatial Development Perspective, ESDP, was approved in Potsdam in 1998, with the aim to provide an integrated, multi-sector strategy for spatial development of Europe. The objectives of ESDP were important to several urban regeneration programs in several cities. EU programs with more connections with urban regeneration include Jessica and Jeremie. Jessica (Joint European Support for Sustainable Investment in City Areas) is focused on sustainable investment growth and employment in European urban areas. It evolved out of the European Strategic Guidelines report. Jeremie (Joint 
Figure 6

Continuous promenade Irwell River, Manchester - before

Figure 7

Continuous promenade Irwell River, Manchester - after

Figure 8 Urban Regeneration of an Industrial Area, Hammarby Sjostad, Stockholm

Figure 9

Urban Regeneration of an Industrial Area, Hammarby Sjostad, Stockholm

Figure 10

EAST Berlin Housing Regeneration
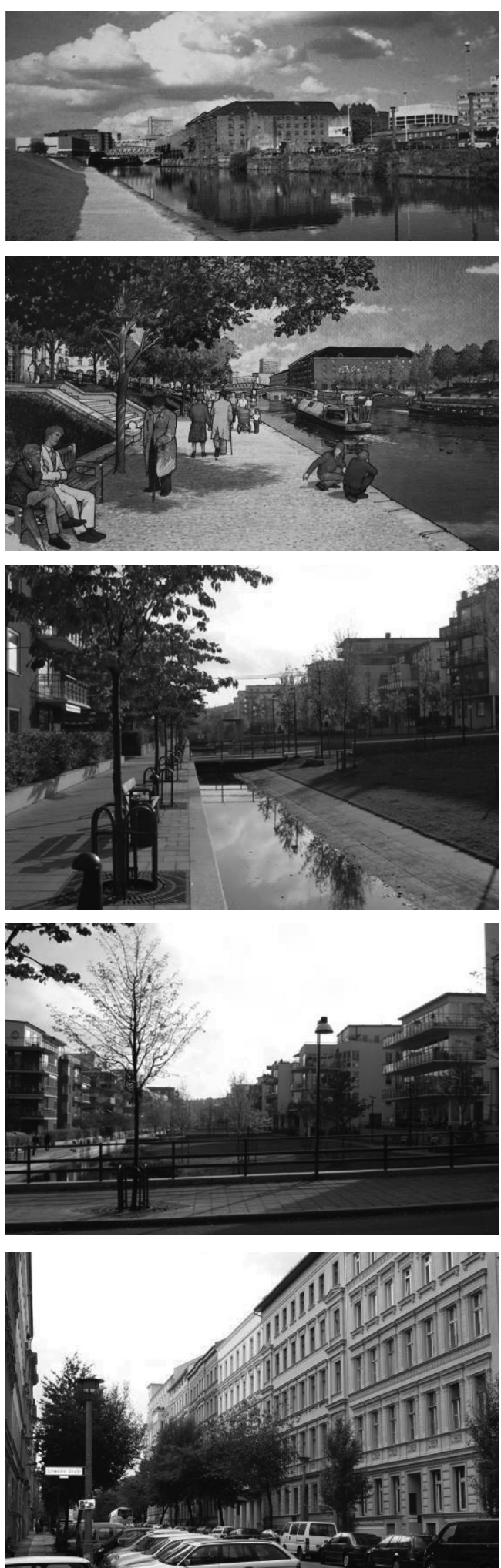

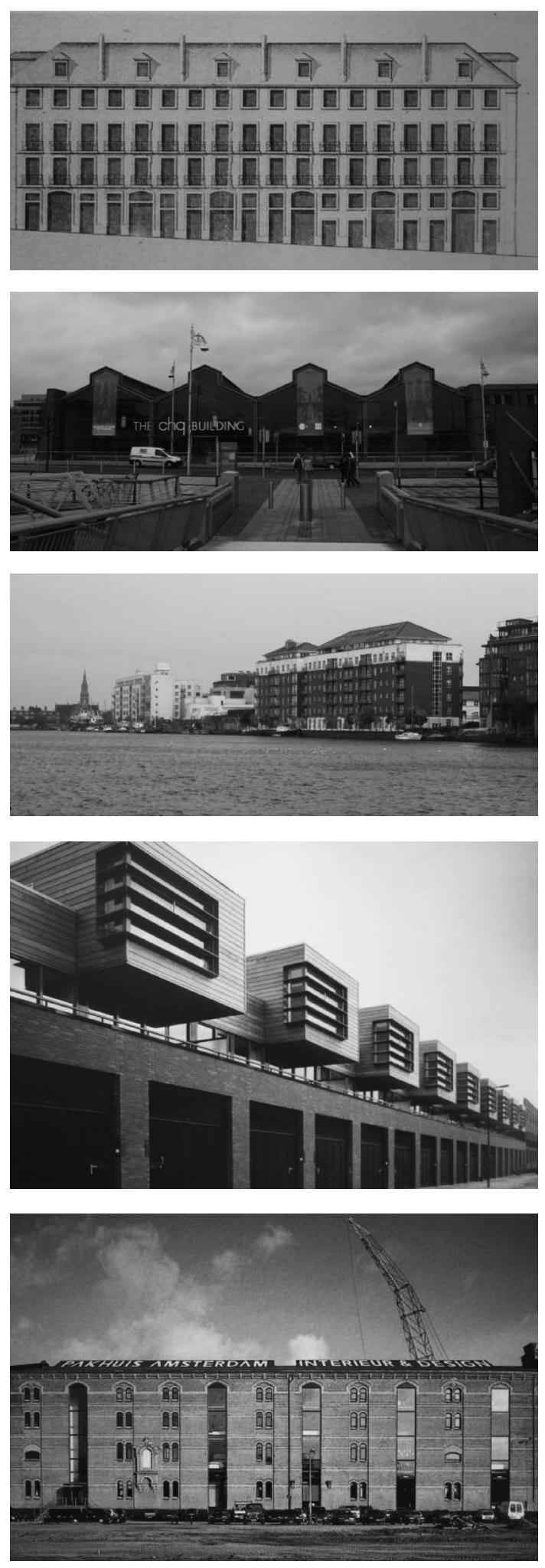

Figure 11

Lisbon building rehabilitation - Project

Figure 12

Dublin Waterfront Regeneration

Figure 13

Dublin Waterfront Regeneration

Figure 14

Housing in Borneo Sporenburg, Eastern Harbor District Amsterdam

Figure 15

Housing in Borneo Sporenburg, Eastern Harbor District Amsterdam 
European Resources for Micro to Medium Enterprises) and focused on start ups, new technologies, innovation and technology transfer to small and medium size enterprises.

\section{URBAN REGENERATION TODAY}

Urban Regeneration is related to:

- "a better understanding of the process of decline" and an "agreement on what one is trying to achieve and how" (Lichfield, 1992, p.19);

- "new ways of tackling our problems which focus in a coordinated way on problems and on the areas where those problems are concentrated" (Donnison, 1993, p.18);

- "policies that attempt to render derelict and vacant land and buildings to beneficial use, create new forms of employment where jobs have been lost, improve the urban environment, and tackle an array of urban social problems" (Couch, C., 2003, pref.).

Urban regeneration is the key to delivering a "comprehensive and integrated vision and action which leads to the resolution of urban problems and which seeks to bring about a lasting improvement in the economic, physical, social and environmental condition of an area that has been subject to change" (Roberts, P.,2006, p.16 and 17). It is composed of six themes:

- the connections between economic, physical and social solutions,

- the physical replacement of many local urban elements,

- the economic development success for the urban prosperity,

- the best possible urban use and minimizing the need for urban expansion and greenfield development,

- the importance of political forces and dominant social conventions,

- the application of the principles of sustainable development.

Urban regeneration includes different main themes:

- revitalization of life in towns and cities,

- promotion of sustainable solutions,

- economic development,

- solution to social problem areas,

- environmental actions,

- accessibility and connectivity.

The key areas of focus for urban regeneration include main areas:

- city and town centers, 
- inner towns and cities,

- areas suffering housing market failure and abandonment,

- peripheral housing areas,

- old industry areas: harbors, airports, coal fields, rail yards, power stations,

- areas of degraded and polluted environments.

The experience of Urban Regeneration in some European cities may conclude that the key issues are (Couch, C. 2003 p. 208):

- the approach of regeneration in the globalized economy,

- the need to promote an attractive image of the area,

- the need for cooperation between cities and regions,

- the importance of long-term and new forms of partnership,

- the integration of sustainable policy goals,

- the potential of culture projects,

- the benefits of new industry, educational and research institutions,

- the importance of social inclusion policies and foster social capital,

- the importance of green infrastructure.

The Sense of Place gives special character, identifies the city and retains and attracts population and tourists. It is essential that urban regeneration includes an integrated and comprehensive solution and a strategic process. (Roberts, P., 2006, p. 22).

The process of urban regeneration mobilizes a wide range of actors and stakeholders including the EU, national, regional and local governments, local communities, corporate business, investors and construction companies, property owners, real estate investors, financial and economic organizations, social and environmental organizations, teaching, innovative and research institutions, but most of all the local community.

Urban regeneration initiatives have been analyzed and published for several Regions, Cities and Towns. These include such diverse places Milan, Amsterdam, Paris, London, Hamburg, Rotterdam, Ruhr region, Glasgow, Dortmund, Montpellier, Barcelona, Belfast, Glasgow, Manchester, Rennes, Seville, Lille, Dundee, Charleroi, Liverpool, Walloon region, Utrecht, Edinburgh, Berlin, Antwerp, Bilbao, Brussels and Chester.

The experience has proved that the following characteristics are very important:

- the location is very important for the accessibility of citizens, workers 
Figure 16

Giraldo Square, Evora Portugal

Figure 17

Medieval Aqueduct, Evora Portugal

Figure 18

Beatrixbrug Holand

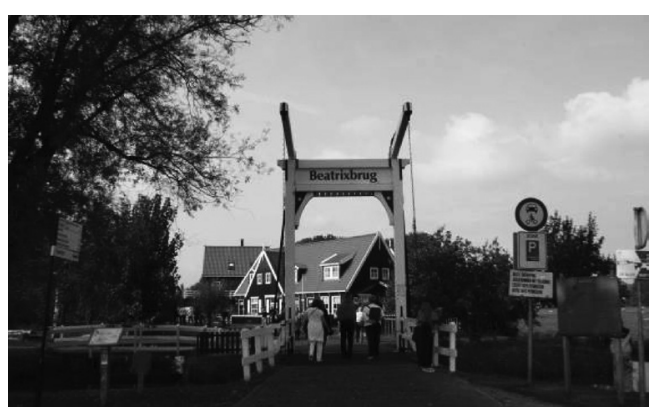

Figure 19 Beatrixbrug Holand

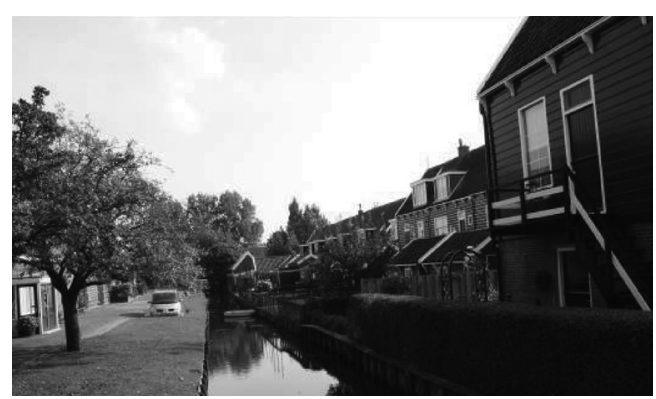



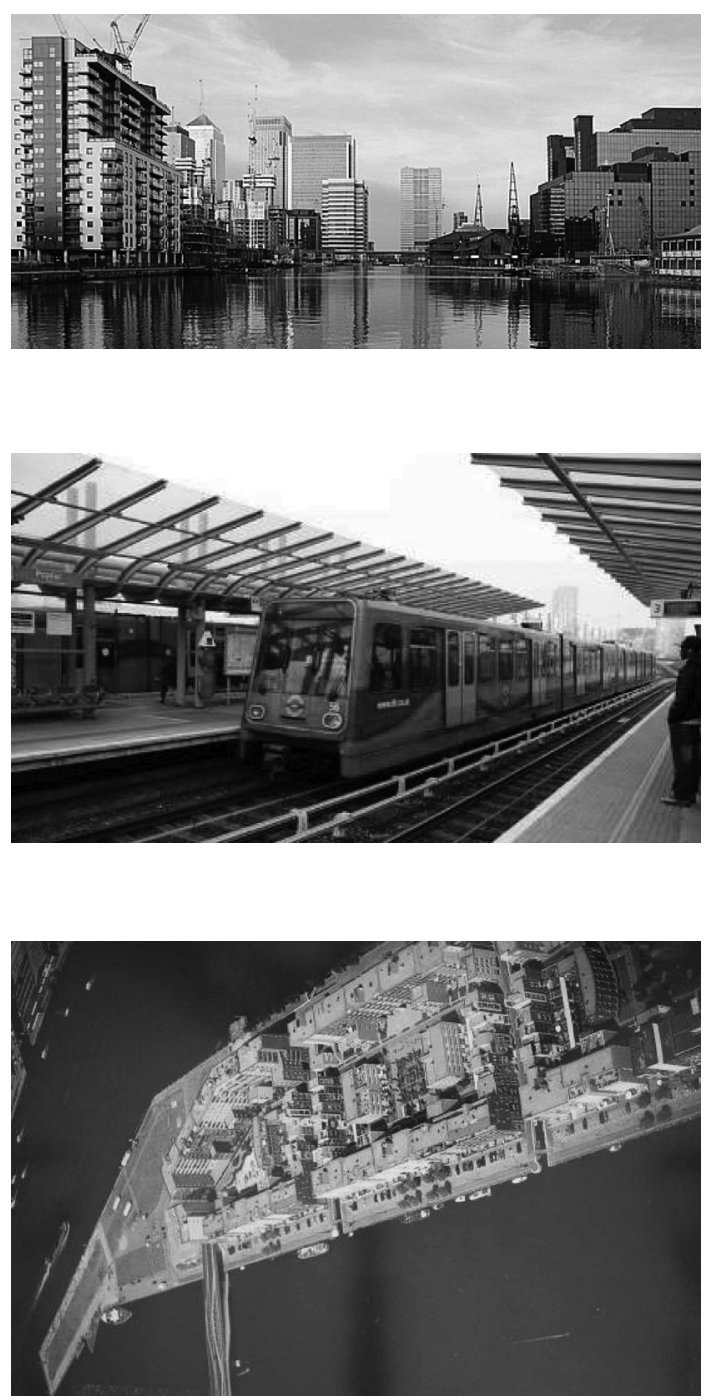

Figure 20

Docklands Regeneration - London

Figure 21

Docklands light rail - London

Figure 22

Java Island Eastern Harbour District Amsterdam - after 
and tourists, advantages of the location of new activities, such as tourism, culture, leisure and services; central places are generally more attractive than peripheral ones,

- the objectives of regeneration,

- the attractiveness of the landscape, people and of investments,

- the existing heritage,

- the economic reconstruction, the strength of local markets and regional national and global economy,

- the rail or motorway, port, energy, ICT and airport infrastructure,

- the existence of a regional and national urban policy.

The study of several urban regeneration initiatives in several cities in Europe concluded that what was also important was the stability of direction, financing and organizational cohesion (Couch, C. 2003 p. 199). In some circumstances special delivery vehicles are needed to deliver large scale regeneration projects such as urban development corporations or by enterprise zones.

Strong planning frameworks are essential for effective and sustainable regeneration. They provide confidence to investors and communities affected by regeneration. They are most effective when they are complemented by a range of supporting policies and programs.

Marketing strategies are an important component at different levels and phases. To attract investment in the first phase. To attract activities, faculties, high-tech enterprises, scientific and research institutions, technology centers, cultural facilities, innovative complexes, while the site is in reconstruction. To retain and attract citizens, workers and tourists after everything has been finalized.

Social inclusion policies are essential to fight unemployment, low preparation for labor market, homelessness, etc. Promoting employment, training, education, health and building up capacity and participation in society.

Urban regeneration should have a holistic and integrated approach to be able to solve the problems of the area and contribute to resolving several problems of the city and the region.

Urban regeneration should also meet the challenge of sustainability. At the European level there are several programs and projects, including the Fifth and the Sixth Environmental Action Programs, the Sustainable Cities and Towns Campaign and the Aalborg Charter. Several countries have a National 
Development Sustainable Strategy. In urban regeneration sustainable urban development can assume different forms such as: achieving a better relationship between the distribution of people and jobs, more sustainable patterns of urban form, the reduction in the need for urban expansion, the brownfield and contaminated sites cleanup, ecological planning principles in the master plan, in the infrastructures and in the construction projects, sustainable drainage, flood management, renewable energy schemes, and in the new activities like converting disused buildings into, business and research parks, museums, or creating green and recreation zones; and maximizing densities and promoting public transportation, cycling and pedestrian safety.

State institutions need private investment, the experience and the risk to deliver urban regeneration. The institutions involved should be managed having in mind public and private interests of several organizations that is known as cross sector long-term partnerships.

Financial investment and funding for regeneration redevelopment is essential for these long term investments. Without state help and EU funding it is more difficult to proceed with the urban regeneration in European Cities and Towns.

\section{CONCLUSION}

All European cities need urban regeneration. Sustainable Urban Regeneration can make an enormous contribution to the resolution of main problems such as the current economic situation, global warming, energy consumption, social exclusion and urban decline. This can only be achieved if concerted action is taken across all European countries.

The principles of urban regeneration are well established. The experience of urban regeneration in European Cities and Towns has been well proven. The current and medium term prospects for the economic situation need an incentive for sustainability. European Cities and Towns need to make an enormous contribution to the recovery of European economic problems through their regeneration.

There is, therefore, a need for a greater level of urban regeneration to help deliver the European goals of economic growth, sustainability and social inclusion. Experience has shown the benefit of European programs applied to Cities and Towns. There is therefore an opportunity for the creation of a European program to provide dynamics to Urban Regeneration all over Europe to deliver the required Urban Renaissance. 
More than an Urban Program it shall be a program for Urban Renaissance that will give a new impulse to urban prosperity, the seed of the future, the glory of the past recovered for future generations. The preparation of European Towns and Cities for the Future.

\section{URBAN RENAISSANCE}

ECTP-CEU proposal is that this program will be designated: URBAN RENAISSANCE PROGRAM. ECTP-CEU is willing to assist EU authorities and the Committee of the Regions in the design of such a program. To achieve this objective the Urban Renaissance Program shall have a budget that is, at least, ten times the budget of Urban I and II to move the European effort in this field from a series of useful localized projects to a transformative program reaching out and having an impact on all areas.

The objectives of urban regeneration shall:

- promote the overall prosperity, equality and competitiveness of cities, towns and regions;

- contribute to the achievement of sustainable development;

- preserve the heritage values and the uniqueness of place of cities and towns and make new activities dynamic as motors of development;

- enhance the cities and towns through a variety of sustainable solutions as efficient energy, efficient use of resources, mobility, air quality, compact city, higher urban densities, expansion control, flexible solutions, mixed use, eco-cycle infrastructures, local shopping and biodiversity;

- help solve economic, social, physical, environmental, housing, transportation and health problems in a strategic, integrated, comprehensive and sustainable way;

- mobilize and upgrade the contributions of culture, knowledge, innovation, new industries and recreation to the urban regeneration;

- identify actions that can enhance sustainability, contribute to economic growth and promote social inclusion;

- turn problem areas into opportunities for creating sustainable urban development;

- mobilize participation, from the outset, of all partners and stakeholders, communities involved and local communities.

Urban regeneration Program shall be based on the following operational parameters:

- a detailed analysis of the area within the context of the functional city and the wider region, 
- a comprehensive vision and strategy of the area, providing an integrated vision and the strategy for the development of the city and the region, with the reference to the national urban policy, based on sustainable principles;

- a related integrated delivery strategy, plan and actions, including economic and financial issues, new activities, employment, education, training, physical and environmental aspects, health, social and community issues, and housing and transportation issues, with the most possible consensus and cooperation, through the participation of all the stakeholders: professional, political, social and financial, stakeholders, community members and neighborhood communities, that guaranties an improvement in the quality of urban life;

- a clear emphasis on how actions, mechanisms and resources, will contribute to achieve the vision and the objectives;

- a "contract" identifying all partners, their means of engagement, their activities, the financial contributions, programs and outcomes;

- vertical and horizontal integration of activities and resources and cooperation of all partners, including statutory authorities;

- a great emphasis on urban design and quality;

- clear and operational short, medium and long term objectives and goals, quantified wherever possible, and with milestones of progress;

- a solid institutional basis, with a strategic commitment at the local, regional and national levels, to deliver economic and finance stable resources;

- a monitoring and evaluation system of urban regeneration, quantified wherever possible, including sustainable indicators, to analyze the achievement of objectives and of sustainability, to revise the programs when and if necessary, and to disseminate the information. 
Buchoud, N., 2008 - La Ville Stratégique, Changer l’Urbanisme pour Répondre aux Défis Urbains Mondiaux. CERTU, 272p.

Ceballos, S., 2004 - "The Role of the Guggenheim Museum in the Development of Urban Entrepreneurial Practices in Bilbao" - International Journal of Iberian Studies, volume 16, $\mathrm{n}^{\circ}$ 3, pp. 177-186.

Comité D’Évaluation et Suivi de L'Agence Nationale pour la Rénovation Urbaine, 2006. De nouvelles Perspectives pour la Rénovation Urbaine Rapport D’Évaluation 2006, La Documentation Française, 93 p.

Comité D’Évaluation et Suivi de L'Agence Nationale pour la Rénovation Urbaine, 2008. Rénovation Urbaine 2004-2008 Quels moyens pour quels Résultats?, La Documentation Française, $146 \mathrm{p}$.

Couch, C., Fraser C., Percy S., 2003. Urban Regeneration in Europe, Blackwell Publishing, 234 p. Doratti, N., 2005 - "Revitalizing Historic Urban Quarters: a Model for Determining the Most Relevant Strategic Approach”. European Planning Studies, volume 13, n5, pp. 749-772.

Drewe, P., Klein, J. L., Hulsbergen E., 2008 - The Challenge of Social Innovation in Urban revitalization. Techne press, $272 \mathrm{p}$.

Godet, M., Sullerot, E., 2005. La Famille, une Affaire Publique. La Documentation Française, $467 \mathrm{p}$.

Grodash, C., Loukaitou-Sideris, A., 2007 - "Cultural Development Strategies and Urban Revitalization”, International Journal of Cultural Policy, volume 13, n 4, pp.349-370.

Healey, P., De Magalhães, C. and Madanipour, A. 2000 - "Institutional Capacity-Building, Urban Planning and Urban Regeneration Projects", Futura volume 18 n³, pp. 117-137.

Jones, P., Evans, J., 2008. Urban Regeneration in the UK, SAGE Publications, p.190.

Kirszbaum, T., 2008 - Rénovation Urbaine les Leçons Americaines. Presses Universitaires de France, p. 86 .

Landry, C., 2008. The Creative City: a Toolkit for Urban Innovators. Eathscan.

Paris, D., Mons, D., 2009. Lille Métropole, Laboratoire du Renouveau Urbain. Parenthèses, p. 269.

Porter, L., Barber, A., 2007 - "Planning the Cultural Quarter in Birmingham's Eastside. European Planning Studies, volume 15, no 10,pp. 1327-1348.

Roberts, P., Sykes, H., 2006. Urban Regeneration a Handbook. Sage Publications, 336 pages.

Spaans, M., 2002. The Implementation of Urban Revitalization Projects. An International Comparison, Delft University Press.

Tiesdell, S., Taner, O., Heath, T., 1996. Revitalizing Historic Urban Quarters. Architectural Press, p. 234. 